\title{
Serum uric acid level is associated with type 2 diabetes mellitus and diabetic regulation
}

\author{
Burcin Meryem Atak, Tuba Taslamacioglu Duman, Mehmet Zahid Kocak, Haluk Savli \\ Bolu Abant Izzet Baysal University Hospital, Department of Internal Medicine, Bolu, Turkey
}

\section{ABSTRACT}

Aim: Serum uric acid is a risk factor for cardiovascular and renal diseases. The role of uric acid as a renal and cardiac risk factor is more prominent in subjects with diabetes mellitus and hypertension. In present retrospective analyze, we aimed to compare serum uric acid levels of subjects with well and poorly controlled type 2 diabetes mellitus (T2DM) and healthy population.

Methods: Patients with T2DM, who admitted to outpatient clinics of our institution between April 2017 and January 2018 were retrospectively analyzed. Diabetic subjects grouped into well or poorly regulated T2DM groups according to the HbA1c level (patients with an $\mathrm{HbA1c}$ lower than 7\% were grouped as well regulated while others grouped as poorly regulated T2DM). Control subjects were healthy individuals whom asked for a routine check-up in our institution. Clinical and laboratory parameters of the study groups compared.

Results: Serum uric acid levels of well-controlled T2DM, poorly controlled T2DM and control groups were $5.9 \pm 1,6.7 \pm 1.8$ and $4.3 \pm 1 \mathrm{mg} / \mathrm{dL}$, respectively $(\mathrm{p}<0.001)$. Post Hoc analysis revealed that uric acid levels of well controlled diabetics were significantly lower than the uric acid levels of poorly controlled diabetics $(\mathrm{p}=0.04)$ and significantly higher than that of the control subjects $(\mathrm{p}<0.001)$.

Conclusion: We suggest that elevated uric acid indicates a cellular level of damage and can be used as a prognostic indicator of pre-diabetes and T2DM.

Keywords: Uric acid; HbA1c; type 2 diabetes mellitus.

Copyright (C) 2018 experimentalbiomedicalresearch.com

Corresponding Author: Dr. Burcin M. Atak,

Bolu Abant Izzet Baysal University Hospital, Department of Internal Medicine, 14280, Golkoy, Bolu, Turkey

E-mail: burcinatak@hotmail.com

ORCID ID: https://orcid.org/0000-0003-4201-9757

Received 2018-09-04, Revisions 2018-09-12

Accepted 2018-09-13

Publication Date 2018-10-01

\section{Introduction}

Serum uric acid is a risk factor for cardiovascular and renal diseases [1]. The role of uric acid as a renal and cardiac risk factor is more prominent in subjects with diabetes mellitus and hypertension. Authors suggested serum uric acid levels as a predictor of worse outcome in stroke, atherosclerotic heart diseases and cerebrovascular conditions [2-4]. 
In addition, fasting plasma glucose was correlated with serum uric acid levels in healthy population [5]. Studies in literature proposed serum uric acid levels as a risk factor for type 2 diabetes mellitus (T2DM) [6,7]. In a more recent study, authors suggested that subjects with higher serum uric acid are more prone to develop T2DM compare to those with lower uric acid levels [8].

In present retrospective analyze, we aimed to compare serum uric acid levels of subjects with well and poorly controlled T2DM and healthy population.

\section{Methods}

Patients with T2DM, who admitted to outpatient clinics of our institution between April 2017 and January 2018 were retrospectively analyzed after obtaining approval of institutional directory board. Diabetic subjects grouped into well or poorly regulated T2DM groups according to the HbA1c level (patients with an HbA1c lower than $7 \%$ were grouped as well regulated while others grouped as poorly regulated T2DM). Subjects with a history or evidence of recent infectious disease, with hematologic or oncologic diseases that may effect serum uric acid levels, or subjects with advanced chronic kidney disease were excluded. Control subjects were healthy individuals whom asked for a routine check-up in our institution.

Age, gender, body weight, waist circumference, height, systolic and diastolic blood pressure of the participants obtained from patient files of our clinic. A body mass index (BMI) simply calculated by the division of weight by the square of height.

Serum uric acid, fasting plasma glucose, triglyceride, total, HDL and LDL cholesterol, HbAlc, serum creatinine levels were recorded.
Statistical analyses were done with SPSS software (SPSS 11.0 for windows, IBM Co, Chicago, IL, USA). Homogenity of variables were conducted with Kolmogorov-Smirnov test. Variables that show normal distribution between study groups were analyzed with ANOVA test and expressed as mean \pm Standard deviation. Variables that not show normal distribution were conducted with Kruskall- Wallis test and expressed as median (min-max). Categorical variables were analyzed with chi-square test. The $p$ value is divided by the number of comparisons as the three groups are compared (Bonferonni correction).

\section{Results}

Study population was consisted of 123 patients; 30 in well-controlled T2DM group, 48 in poorly controlled T2DM group and 45 in control group. Mean age of the subjects in well-controlled T2DM, poorly controlled T2DM and control groups were 54 (43-66), 54 (35-65) and 52 (30-59) years, respectively $(p=0.04) .20$ of 30 in well controlled T2DM group, 24 of 48 in poorly controlled T2DM group and 31 of 45 in control group were women. Gender distribution was not statistically different between study groups $(p=0.13)$.

Serum uric acid levels of well-controlled T2DM, poorly controlled T2DM and control groups were $5.9 \pm 1.6,7 \pm 1.8$ and $4.3 \pm 1$ $\mathrm{mg} / \mathrm{dL}$, respectively. There was a significant difference between groups in terms of serum uric acid levels $(p<0.001)$. Post Hoc analysis revealed that uric acid levels of well controlled diabetics were significantly lower than the uric acid levels of poorly controlled diabetics $(p=0.04)$ and significantly higher than that of the control subjects $(p<0.001)$. The $\mathrm{p}$ value is 
divided by the number of comparisons as the three groups are compared (Bonferonni correction).

\section{Discussion}

The most important consequence of this study is that serum uric acid levels are higher in type 2 diabetic patients compared to the control group. Another important finding is that serum uric acid levels in well-controlled diabetics are lower than those in T2DM patients with poor metabolic control.

Many chronic diseases and complications such as T2DM may cause great economic burden all over the world. T2DM is a chronic metabolic disease characterized by relative or absolute insufficiency of insulin secretion and / or impaired carbohydrate, lipid and protein metabolism, which affects quality and duration of life due to complications and characterization with insulin resistance. Prevalence of T2DM increases and threatens public health via diabetes related complications.

Type 2 Diabetes Mellitus is characterized with hyperinsulinemia, which enhances uric acid retention [9]. Uric acid is the final degradation product of purine metabolism. It has recently been observed that uric acid causes cell damage to the cell membrane with effects such as oxidation and inflammation [10,11]. Studies have found that DM, metabolic syndrome, hypertension and obesity are high in people with high uric acid levels [12-14]. If uric acid is excluded, other factors may help in the development of diabetes and the prognosis of diabetic patients. In this study we also compared healthy control patients with regular and non-regular diabetic patients. In our study, uric acid averages were $6.65 \mathrm{mg} / \mathrm{dL}$ in the highest non-regular diabetic patients. When the groups are compared, the level of regulation is impaired and the uric acid level increases as shown in other studies. This highest detected mean hyperuricemia $(6.5 \mathrm{mg} / \mathrm{dl}$ in female, $6 \mathrm{mg} / \mathrm{dl}$ in male) was close to the level we were referring to. Antioxidants can be prooxidant in certain situations [15].

It is known that uric acid acts as an antioxidant in the early stages of the atherosclerotic process and is the strongest determinant of plasma antioxidant capacity [16]. However, when the levels of serum acid are increased to $6 \mathrm{mg} / \mathrm{dl}$ in women and 6.5-7.0 mg / dl in men in the later stages of the atherosclerotic process, this antioxidant state paradoxically becomes prooxidant. This paradoxical condition seems to depend on several environmental factors such as the stage of the disease process, tissue and substrate localization, acidity, oxidant environment, other local antioxidant decrease, oxidant and enzyme release and medium availability [17]. In another study on type $1 \mathrm{DM}$, oxidative stress was also shown to be increased by the effect of nitric oxide in cases where the uric acid level fell below $3 \mathrm{mg} / \mathrm{dL}$ [18]. In a recent study, authors found that serum uric acid levels of well controlled type 2 diabetic subjects were significantly lower than the uric acid of poorly controlled T2DM patients [19]. Similarly, we also report that poorly controlled diabetics have significantly higher uric acid levels compared to well controlled diabetic subjects. Relatively small population is a limitation of present study. Another limitation is the retrospective design of our work.

In conclusion, according to the results of the studies, uric acid is an antioxidant substance and oxidative stress and diabetic complications increase when it falls below $3 \mathrm{mg} / \mathrm{dl}$. However, it affects as prooxidant in cases exceeding $6 \mathrm{mg} / \mathrm{dL}$. Therefore, we suggest that elevated uric acid indicates a cellular level 
of damage and can be used as a prognostic indicator of pre-diabetes and T2DM.

\section{Conflict of Interest: No conflict of interest was} declared by the authors.

\section{References}

[1]Hayden MR, Tyagi SC. Uric acid: A new look at an old risk marker for cardiovascular disease, metabolic syndrome, and type 2 diabetes mellitus: The urate redox shuttle. Nutr Metab (Lond). 2004;1(1):10.

[2]Niskanen LK, Laaksonen DE, Nyyssonen K, Alfthan G, Lakka HM, Lakka TA et al. Uric acid level as a risk factor for cardiovascular and all-cause mortality in middle-aged men: a prospective cohort study. Arch Intern Med. 2004; 164(14): 1546-51.

[3]Alderman MH. Uric acid and cardiovascular risk. Curr Opin Pharmacol. 2002; 2(2): 126-30.

[4]Verdecchia P, Schillaci G, Reboldi G, Santeusanio F, Porcellati C, Brunetti P. Relation between serum uric acid and risk of cardiovascular disease in essential hypertension. The PIUMA study. Hypertension. 2000; 36(6): 1072-78.

[5]Facchini F, Chen YD, Hollenbeck CB, Reaven GM. Relationship between resistance to insulin-mediated glucose uptake, urinary uric acid clearance, and plasma uric acid concentration. JAMA. 1991; 266(21): 3008-11.

[6]Brand FN, McGee DL, Kannel WB, Stokes J, 3rd, Castelli WP. Hyperuricemia as a risk factor of coronary heart disease: The Framingham Study. Am J Epidemiol. 1985; 121(1): 11-18.

[7]Herman JB, Goldbourt U. Uric acid and diabetes: observations in a population study. Lancet. 1982; 2(8292): 240-43.
[8]Dehghan A, van Hoek M, Sijbrands EJ, Hofman A, Witteman JC. High serum uric acid as a novel risk factor for type 2 diabetes. Diabetes Care. 2008; 31(2): 36162.

[9]Hayden MR, Tyagi SC. Intimal redox stress: accelerated atherosclerosis in metabolic syndrome and type 2 diabetes mellitus. Atheroscleropathy. Cardiovasc Diabetol. 2002; 1: 3

[10] Many A, Hubel CA, Roberts JM. Hyperuricemia and xanthine oxidase in preeclampsia, revisited. Am J Obstet Gynecol. 1996; 174(1Pt 1): 288-91.

[11] Kato M, Hisatome I, Tomikura Y, Kotani K, Kinugawa $\mathrm{T}$, Ogino $\mathrm{K}$ et al. Status of endothelial dependent vasodilation in patients with hyperuricemia. Am J Cardiol. 2005; 96(11): 1576-78.

[12] Bonakdaran S, Kharaqani B. Association of serum uric acid and metabolic syndrome in type 2 diabetes. Curr Diabetes Rev. 2014; 10(2): 113-17.

[13] Kuwabara M, Kuwabara R, Niwa K, Hisatome I, Smits G, Roncal-Jimenez CA et al. Different risk for hypertension, diabetes, dyslipidemia, and hyperuricemia according to level of body mass index in japanese and american subjects. Nutrients. 2018;10(8). pii: E1011.

[14]Park CE, Sung HH, Jung EY, Moon AE, Kim HS, Yoon H. Gender difference in the relationship between uric acid and pulse pressure among Korean adults. Clin Exp Hypertens. 2018:24: 1-6.

[15]Patterson RA, Horsley ET, Leake DS. Prooxidant and antioxidant properties of human serum ultrafiltrates toward LDL: important role of uric acid. J Lipid Res. 2003; 44(3): 512-21.

[16]Nyyssonen K, Porkkala-Sarataho E, Kaikkonen J, Salonen JT. Ascorbate and 
urate are the strongest determinants of plasma antioxidative capacity and serum lipid resistance to oxidation in Finnish men. Atherosclerosis. 1997; 130(1-2): 223-33.

[17] Naghavi M, John R, Naguib S, Siadaty MS, Grasu R, Kurian KC et al. pH Heterogeneity of human and rabbit atherosclerotic plaques; a new insight into detection of vulnerable plaque. Atherosclerosis. 2002; 164(1): 27-35.

[18]Pitocco D, Di Stasio E, Romitelli F, Zaccardi F, Tavazzi B, Manto A et al. Hypouricemia linked to an overproduction of nitric oxide is an early marker of oxidative stress in female subjects with type 1 diabetes. Diabetes Metab Res Rev. 2008; 24(4): 318-23.

[19]Duman TT, Kocak MZ, Atak BM, Erkus E. Serum Uric acid is correlated with HbA1c levels in type 2 diabetes mellitus. Exp Biomed Res. 2018; 1(1): 6-9. 